\title{
Dietary nitrate lowers ambulatory blood pressure in treated, uncontrolled hypertension: a 7-d, double-blind, randomised, placebo-controlled, cross-over trial
}

\author{
Conor P. Kerley ${ }^{1 *}$, Eamon Dolan ${ }^{2}$, Philip E. James ${ }^{3}$ and Liam Cormican ${ }^{1}$ \\ ${ }^{1}$ Respiratory and Sleep Diagnostics Department, Connolly Hospital, Blanchardstown, Dublin 15, Republic of Ireland \\ ${ }^{2}$ Acute Stroke Unit, Department of Medicine for the Elderly, Connolly Hospital Blanchardstown, Dublin 15, Republic of Ireland \\ ${ }^{3}$ School of Health Sciences, Cardiff Metropolitan University, Llandaff Campus, Western Avenue, Cardiff CF5 2YB, UK
}

(Submitted 26 May 2017 - Final revision received 15 November 2017 - Accepted 8 January 2018)

\section{Abstract}

Dietary nitrate has been shown to increase nitrate/nitrite levels and decrease blood pressure (BP) in multiple populations. There are few reports among hypertensives and these reports have provided conflicting evidence. We aimed to assess the effect of daily nitrate compared with placebo in subjects with uncontrolled hypertension (HTN). On day 0, hypertensives wore an ambulatory BP monitor (ABPM) for $24 \mathrm{~h}$ and blood was taken. Subjects were then randomised to 7-d nitrate-rich beetroot juice $\left(\mathrm{NO}_{3}{ }^{-}\right)(12.9 \mathrm{mmol}$ nitrate) followed by 7-d nitrate-depleted beetroot juice $(0.5 \mathrm{mmol}$ nitrate) or vice versa. ABPM and blood were assessed before and after both conditions. In all, twenty subjects with treated yet uncontrolled HTN entered and completed the trial (mean age $=62.5$ years, mean BMI $=30 \cdot 7 \mathrm{~kg} / \mathrm{m}^{2}$ ). Baseline BP was $137 / 80(\mathrm{sD} 7 / 7$ ) $\mathrm{mmHg}$. Dietary nitrate was well tolerated and resulted in significantly increased plasma nitrite $(P=0 \cdot 0004)$ and decreased $24-\mathrm{h}$ systolic BP and diastolic BP compared with placebo $(-8 \mathrm{mmHg} ; P=0.012$ and $-4 \mathrm{mmHg} ; P=0.018$, respectively). Our results support the existing data suggesting an anti-hypertensive effect of dietary nitrate in treated yet uncontrolled hypertensives. Targeted dietary strategies appear promising contributors to BP control.

Key words: Dietary nitrate: Nitrite: Nitric oxide: Hypertension: Blood pressure

Hypertension (HTN) affects >one billion people. Despite advances, blood pressure (BP) remains uncontrolled in approximately $50 \%$ of individuals treated with medication ${ }^{(1,2)}$. There is a need for novel, effective therapies for primary and secondary prevention of HTN.

Nitric oxide (NO) is a major vasodilating molecule and plays a critical role in vascular homoeostasis and $\mathrm{BP}$ regulation ${ }^{3}$. Reduced NO bioavailability, either through decreased production or increased consumption, has been associated with endothelial dysfunction and implicated in the development of prehypertension $^{(4)}$ and $\mathrm{HTN}^{(5)}$. Multiple studies have demonstrated that plasma and/or urinary NO metabolites are significantly lower in hypertensives compared with matched controls $^{(6-11)}$. In addition, NO levels correlate positively with vascular function $^{(11)}$ and peak brachial artery dilation ${ }^{(12)}$, but negatively with $\mathrm{BP}^{(7,9)}$. Thus, the restoration of $\mathrm{NO}$ signalling provides an attractive mechanism to control HTN.

Dietary nitrate has been suggested to be an important contributor to NO signalling in humans, with the first human report of an anti-hypertensive effect in 2006. A 3-d double-blind, cross-over study of $0.1 \mathrm{mmol} / \mathrm{kg}$ per $\mathrm{d}$ sodium nitrate resulted in a significant 3.7-mmHg reduction in diastolic BP (DBP) in young, healthy volunteers $^{(13)}$. A 2008 study demonstrated marked hypotensive effect of $\mathrm{NO}_{3}{ }^{-}(-10 \cdot 4 / 8 \mathrm{mmHg})$, which correlated with increased plasma nitrite ${ }^{(14)}$.

Since then, research regarding dietary nitrate and CVD has increased. Indeed, several reviews have detailed the existing preclinical/clinical evidence, as well as possible mechanisms, for dietary nitrate and its potential role in $\mathrm{BP}$ regulation ${ }^{(15-19)}$. A 2013 systematic review and meta-analysis concluded that dietary nitrate can reduce systolic BP (SBP) by $4.4 \mathrm{mmHg}$ $(P<0.001)$ and DBP by $1.1 \mathrm{mmHg}(P=0.06)^{(16)}$. This and another review $^{(17)}$ noted inverse associations between nitrate dose of SBP reduction $\left(r^{2} 0.45 ; P=0.033\right)$. However, it is important to note that these reviews focused mostly on normotensive, healthy, normal-weight males in acute interventions and there is a lack of data regarding hypertensives.

Nonetheless, high habitual intake of dietary nitrate has been inversely associated with HTN risk ${ }^{(20,21)}$. Further, a proofof-principal study in fifteen untreated, grade 1 hypertensives

Abbreviations: ABPM, ambulatory blood pressure monitor; BP, blood pressure; DBP, diastolic blood pressure; HTN, hypertension; NO, nitric oxide; $\mathrm{NO}_{3}^{-}$, nitrate-rich beetroot juice; PL, placebo; SBP, systolic blood pressure.

* Corresponding author: C. P. Kerley, fax +353 831458796, email conorkerley@gmail.com 
demonstrated that a single nitrate dose $(3.5 \mathrm{mmol}$ as beetroot juice) increased plasma nitrite by $150 \%$ and decreased $24-\mathrm{h} \mathrm{BP}$ $(-11.2 /-9.6 \mathrm{mmHg} ; \quad P<0.001)$, as well as arterial stiffness, compared with control $(P<0 \cdot 05)^{(22)}$. In a subsequent unblinded and uncontrolled, pilot study, we demonstrated that 14-d dietary nitrate could increase serum NO metabolites in controlled and uncontrolled hypertensives but selectively lowered BP and arterial stiffness in uncontrolled hypertensives only ${ }^{(22)}$. However, recent randomised controlled trials (RCT) of dietary nitrate in hypertensives provided inconsistent results. One of these RCT demonstrated that 4 weeks of $6.45 \mathrm{mmol}$ dietary nitrate significantly reduced $\mathrm{BP}^{(23)}$. However, a subsequent cross-over RCT reported no effect of 1 week of the same nitrate dose ${ }^{(24)}$.

Considering these inconsistencies, we wanted to follow on from our pilot study and assess, in a more rigorous manner, the effect of 7-d daily dietary nitrate on ambulatory BP, plasma nitrate/nitrite, lipids and renal indices among treated but uncontrolled hypertensives.

\section{Methods}

\section{Trial design}

This was a 7-d, double-blind, randomised, placebo (PL)controlled, cross-over trial to assess the effect of dietary nitrate. Subjects were tested on three separate occasions - baseline (day 1), midpoint (day 8) and endpoint (day 15) - before and after each intervention period (Fig. 1).

\section{Study participants}

Subjects with known or suspected uncontrolled HTN, established on diverse anti-hypertensive regimens, were recruited from specialist clinics and invited to wear an ambulatory BP monitor (ABPM) for $24 \mathrm{~h}$. We excluded subjects with controlled HTN $(<130 /$ $80 \mathrm{mmHg}$ ), as well as those with kidney disease, diabetes, cognitive impairment or sleep apnoea, and those taking organic nitrates. The study was carried out in accordance with the principles of the Declaration of Helsinki and was approved by the Research Ethics Committee of Connolly Hospital, Dublin, Ireland.

\section{Intervention}

This trial used $\mathrm{NO}_{3}{ }^{-}$and nitrate-depleted beetroot juice (PL) as previously described ${ }^{(25)}$. Independent testing and analysis of the $\mathrm{NO}_{3}^{-}$and PL were conducted previously ${ }^{(25)}$ and the specific compositions are displayed in Table 1.

A physician not involved in data gathering (L. C.) generated the allocation sequence, whereas a nutrition researcher enrolled subjects (C. P. K.). After baseline assessments, subjects were randomised to consume $140 \mathrm{ml}$ of $\mathrm{NO}_{3}(12.9 \mathrm{mmol}$ nitrate) at approximately 09.00 hours each morning for $7 \mathrm{~d}$ followed by PL $(0.5 \mathrm{mmol}$ nitrate $)$ for $7 \mathrm{~d}$ or the cross-over condition. We selected this dose as the nitrate content is attainable with a diet rich in vegetables ${ }^{(26)}$

During the trial, all subjects were provided with written and verbal instructions not to alter behaviours that are known to influence NO kinetics, including dietary, tobacco, alcohol,

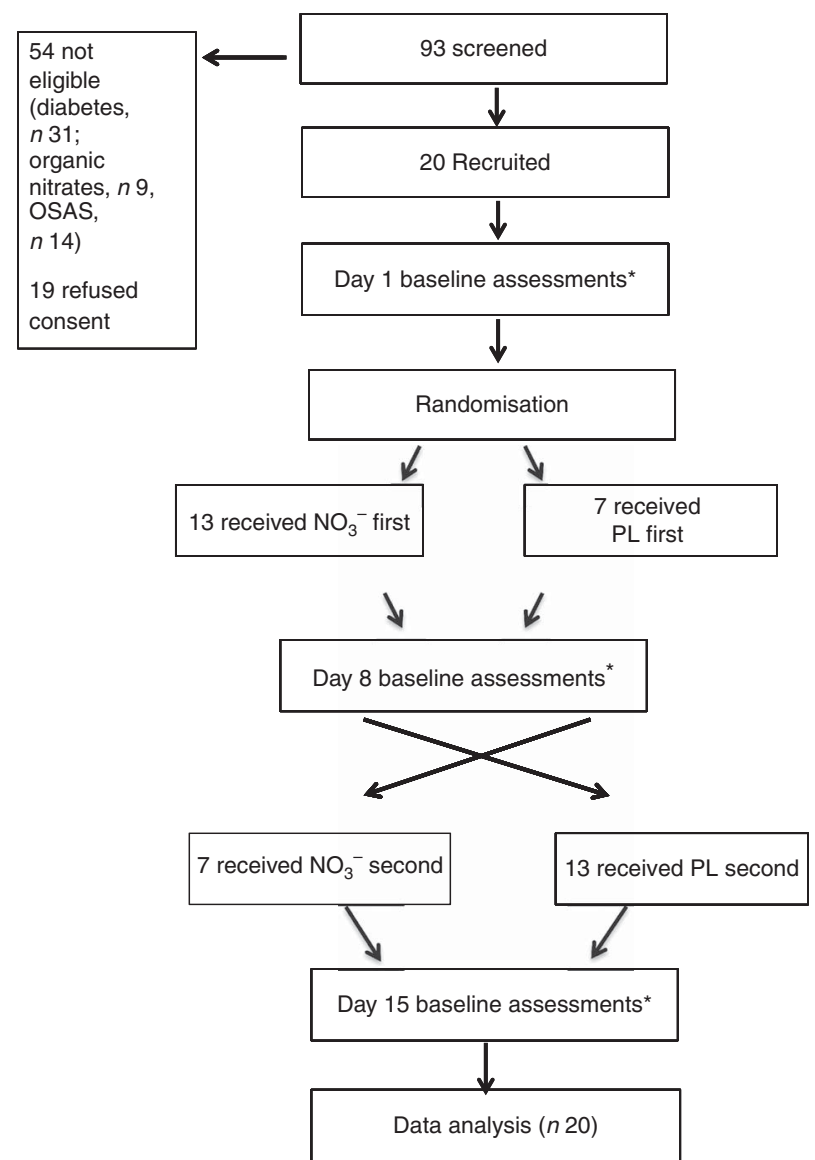

Fig. 1. Trial design. $\mathrm{NO}_{3}^{-}$, nitrate-rich beetroot juice; $\mathrm{PL}$, placebo. * Assessments included 24-h ambulatory blood pressure, blood draw and assessments of dietary nitrate intake.

Table 1. Composition of nitrate-depleted (placebo; PL) and nitrate-rich beetroot juice $\left(\mathrm{NO}_{3}{ }^{-}\right)$

\begin{tabular}{lcc}
\hline & $\mathrm{PL}$ & $\mathrm{NO}_{3}^{-}$ \\
\hline Dose (ml) & 140 & 140 \\
Energy (kJ) & 468.61 & 635.97 \\
Energy (kcal) & 112.42 & 152.46 \\
Carbohydrate (g) & 24.64 & 32.186 \\
Sugars (g) & 24.32 & 30.646 \\
Protein (g) & 2.849 & 5.39 \\
Fat (g) & 0.308 & 0.308 \\
SFA (g) & 0.0077 & 0.0077 \\
MUFA (g) & 0.0077 & 0.00924 \\
PUFA (g) & 0.1386 & 0.1232 \\
Na (mg) & 139.986 & 177.1 \\
K (mg) & 1041.04 & 1424.5 \\
Ca (mg) & 13.244 & 12.705 \\
Nitrate (mmol) (mg) & 0.19 & 12.9 \\
\hline
\end{tabular}

exercise or medication habits and not to use mouthwash or antibiotics, which are known inhibitors of dietary nitrate reduction to nitrite.

Subjects took their seventh and final dose of each beverage $2-3 \mathrm{~h}$ before their midpoint and endpoint assessments. In this manner, the juice was most active during waking hours and testing coincided with peak physiological and biochemical effect ${ }^{(23,27)}$. Compliance with the juice was assessed with a daily diary. 


\section{Outcome measures}

On all 3 testing days (days 1, 8 and 15) in an identical manner and at the same time of day, non-fasting blood was drawn and subjects were fitted with an ABPM for $24 \mathrm{~h}$ as previously described $^{(22)}$.

\section{Lifestyle assessment}

Weekly dietary nitrate intake was estimated at each time point using the "Nitrate Veg Table"(28). This table asks subjects to report how many times in the previous week they consumed foods rich in nitrate and provides a composite score for weekly nitrate intake. At each time point, we also asked detailed questions regarding the subjects exercise, alcohol, medication, tobacco and alcohol habits.

\section{Biochemical analysis}

On testing days, venous blood samples were drawn into serum and plasma tubes that have a low nitrate/nitrite content before ABPM setup. Serum was analysed locally for routine lipid (total cholesterol, LDL, HDL) and renal (sodium, potassium, creatinine) parameters.

The half-life of NO is $<1 s^{(29)}$. Therefore, direct determination of $\mathrm{NO}$ in vivo is difficult. However, measurement of $\mathrm{NO}$ metabolites (nitrate/nitrite) in biological fluids reflects NO bioavailability ${ }^{(30)}$. Therefore, the plasma tube was centrifuged at $4000 \mathrm{rpm}$ and $4^{\circ} \mathrm{C}$ for $10 \mathrm{~min}$ immediately after phlebotomy. Plasma was subsequently immediately extracted into Eppendorf cryovials, frozen at $-80^{\circ} \mathrm{C}$ and later analysed for nitrate/nitrite with the current 'goldstandard', ozone-based chemiluminescence analysis (NO analyser, NOA280i; Sievers), which is the most accurate and sensitive NO metabolite detection method, as previously described ${ }^{(31)}$.

\section{Statistical methods}

The primary outcome was 24-h SBP. Our sample size was based on the primary outcome of mean 24-h ambulatory BP. At $\alpha=0.05$, we estimated that nineteen participants would provide $80 \%$ power, assuming an SD of $3.8 \mathrm{mmHg}$, to detect a $2 \cdot 6-\mathrm{mmHg}$ difference in the mean 24-h ambulatory BP based on our pilot study ${ }^{(23)}$.

The difference between baseline and post-interventions was calculated for all variables, denoted as $\Delta \mathrm{NO}_{3}{ }^{-}$and $\Delta \mathrm{PL}$. Ambulatory BP were analysed by using mixed models in SAS 9.0 software by using the PROC MIXED command (SAS Institute Inc.). The subject was included as a random factor in each model. Fixed effects included the treatment (active or PL) and the order of treatments to account for a possible 'carry over' effect. The statistical difference between $\Delta \mathrm{NO}_{3}{ }^{-}$and $\Delta \mathrm{PL}$ for other outcome variables was calculated using paired $t$ tests. Results were expressed as means and standard deviations. All statistical tests were conducted at the two-sided 0.05 significance level.

\section{Results}

\section{Study population}

Of ninety-three subjects screened, twenty were recruited. There were no dropouts. Baseline characteristics are displayed in Table 2.
The cohort comprised mainly male (65\%), Caucasian (90\%) and obese (mean BMI $=30 \mathrm{~kg} / \mathrm{m}^{2}$ ) individuals, and most had a history of CVD. All subjects were prescribed $\geq 1$ anti-hypertensive medication. There were no reported adverse events. The juices were well tolerated, and as reported previously ${ }^{(14,23,27)}$ fourteen subjects (70\%) reported transient, red/pink urine (beetruria).

\section{Lifestyle results}

Throughout the trial, there was no reported change in prescribed medication, or habitual tobacco/alcohol/exercise habits between visits. Dietary nitrate intakes were constant on both group and individual levels at all three time points (12.2 nitrate 'units' weekly).

\section{Biochemical results}

Plasma nitrite levels increased significantly after $\mathrm{NO}_{3}^{-}$ $(P=0.001)$ but not after PL $(P=0.3)$ (Table 3$)$. There was no difference at any stage between lipid or renal parameters (Table 3).

\section{Ambulatory blood pressure results}

Average ABPM wear time was similar at all three time points with an average of $>30$ successful readings taken. Mean group

Table 2. Baseline characteristics

(Mean values and standard deviations; numbers and percentages)

\begin{tabular}{|c|c|c|}
\hline & Mean & SD \\
\hline$n$ & \multicolumn{2}{|c|}{20} \\
\hline Age (years) & 62.5 & $13 \cdot 1$ \\
\hline \multicolumn{3}{|l|}{ Male, sex } \\
\hline$n$ & \multicolumn{2}{|c|}{13} \\
\hline$\%$ & \multicolumn{2}{|c|}{65} \\
\hline BMI (kg/m²) (range) & $30 \cdot 7$ & 5.8 \\
\hline \multicolumn{3}{|l|}{ Race } \\
\hline \multicolumn{3}{|l|}{ Irish } \\
\hline$n$ & \multicolumn{2}{|c|}{18} \\
\hline$\%$ & \multicolumn{2}{|c|}{90} \\
\hline \multicolumn{3}{|l|}{ Asian } \\
\hline$n$ & \multirow{2}{*}{\multicolumn{2}{|c|}{$\begin{array}{l}1 \\
5\end{array}$}} \\
\hline$\%$ & & \\
\hline \multicolumn{3}{|l|}{ African-American } \\
\hline$n$ & \multicolumn{2}{|c|}{1} \\
\hline$\%$ & \multicolumn{2}{|c|}{5} \\
\hline \multicolumn{3}{|l|}{ Smoking status $(n)$} \\
\hline Current smoker & \multicolumn{2}{|c|}{0} \\
\hline Ex-smoker & \multirow{2}{*}{\multicolumn{2}{|c|}{$\begin{array}{c}8 \\
12\end{array}$}} \\
\hline LLNS & & \\
\hline Years with HTN & 7.5 & 6.5 \\
\hline Baseline SBP (mmHg) & 137 & 7 \\
\hline Baseline DBP (mmHg) & 80 & 7 \\
\hline \multicolumn{3}{|l|}{ Pharmacology } \\
\hline Average no. BP medications & 2 & $1(1$ to 4$)$ \\
\hline Aspirin $(n)$ & \multirow{2}{*}{\multicolumn{2}{|c|}{$\begin{array}{l}6 \\
8\end{array}$}} \\
\hline Statin $(n)$ & & 8 \\
\hline Baseline nitrate intake (units/week) & $12 \cdot 2$ & 7 \\
\hline \multicolumn{3}{|l|}{ Co-morbidities } \\
\hline Cerebrovascular disease $(n)$ & & \\
\hline $\operatorname{CAD}(n)$ & & \\
\hline
\end{tabular}

LLNS, lifelong non-smoker; HTN, hypertension; SBP, systolic blood pressure; $\mathrm{DBP}$, diastolic blood pressure; BP, blood pressure; CAD, coronary artery disease. 
Table 3. Biochemical results

(Mean values and standard deviations)

\begin{tabular}{|c|c|c|c|c|c|c|}
\hline & Baseline & After PL & $\Delta \mathrm{PL}$ & After $\mathrm{NO}_{3}{ }^{-}$ & $\Delta \mathrm{NO}_{3}^{-}$ & $P^{*}$ \\
\hline Nitrite $(\mu \mathrm{M})$ & & & & & & 0.0004 \\
\hline Mean & 126 & 131 & 5 & 732 & 581 & \\
\hline SD & 115 & 134 & & 653 & & \\
\hline CRP (mg/l) & $9 \cdot 31$ & $10 \cdot 35$ & 0.14 & 14 & & 0.37 \\
\hline Bilirubin $(\mu \mathrm{mol} / \mathrm{l})$ & $13 \cdot 8$ & 14.8 & -1 & $15 \cdot 9$ & 0.13 & \\
\hline ALT (IU/I) & 38.5 & $32 \cdot 3$ & $-6 \cdot 2$ & 35.4 & $-3 \cdot 1$ & 0.1 \\
\hline ALP (IU/I) & $86 \cdot 6$ & 82.5 & $-4 \cdot 1$ & $78 \cdot 2$ & -8.4 & 0.24 \\
\hline GGT (IU/I) & 55.9 & $55 \cdot 2$ & -0.7 & $56 \cdot 3$ & 1.4 & 0.45 \\
\hline Total cholesterol $(\mathrm{mmol} / \mathrm{l})$ & 4.6 & 4.67 & 0.7 & 4.57 & -0.03 & 0.25 \\
\hline LDL-cholesterol (mmol/l/) & 2.5 & 2.54 & 0.4 & $2 \cdot 34$ & -0.16 & 0.1 \\
\hline HDL-cholesterol (mmol/l) & 1.4 & 1.47 & 0.7 & 1.51 & 0.11 & 0.37 \\
\hline TAG (mmol/l) & 1.49 & 1.42 & -0.07 & 1.42 & -0.07 & 0.33 \\
\hline $\mathrm{Na}^{+}(\mathrm{mmol} / \mathrm{l})$ & 140 & $140 \cdot 3$ & 0.3 & $140 \cdot 2$ & 0.2 & 0.19 \\
\hline $\mathrm{K}^{+}(\mathrm{mmol} / \mathrm{l})$ & 4.7 & 4.9 & 0.2 & $5 \cdot 1$ & 0.4 & 0.24 \\
\hline Creatinine $(\mathrm{mmol} / \mathrm{l})$ & 76.9 & 78.9 & 2 & $77 \cdot 1$ & 0.2 & 0.13 \\
\hline Urate $(\mu \mathrm{mol} / \mathrm{l})$ & 331.4 & $323 \cdot 8$ & -7.6 & 331.3 & -0.1 & 0.26 \\
\hline
\end{tabular}

Table 4. Ambulatory blood pressure $(A B P)$ results

(Mean values and standard deviations; differences and 95\% confidence intervals)

\begin{tabular}{|c|c|c|c|c|c|c|c|c|c|c|c|}
\hline & \multirow[b]{2}{*}{ Baseline } & \multicolumn{2}{|c|}{ After PL } & \multicolumn{2}{|c|}{$\Delta \mathrm{PL}$} & \multicolumn{2}{|c|}{ After $\mathrm{NO}_{3}^{-}$} & \multirow{2}{*}{$\frac{\Delta \mathrm{NO}_{3}{ }^{-}}{\text {Mean }}$} & \multirow{2}{*}{$\begin{array}{l}\text { Differences in treatment } \\
\text { groups }(\mathrm{mmHg})\end{array}$} & \multirow[b]{2}{*}{$95 \% \mathrm{Cl}$} & \multirow[b]{2}{*}{$P^{*}$} \\
\hline & & Mean & SD & Mean & SD & Mean & SD & & & & \\
\hline $24 \mathrm{~h}$ SBP $(\mathrm{mmHg})$ & 137 & 7 & 133 & 9 & -4 & 129 & 9 & -8 & $-4 \cdot 4$ & $-8.7,0.1$ & 0.044 \\
\hline $24 \mathrm{~h}$ DBP $(\mathrm{mmHg})$ & 80 & 7 & 79 & 8 & -1 & 76 & 8 & -4 & $-3 \cdot 2$ & $-6 \cdot 1,-0 \cdot 3$ & 0.032 \\
\hline Day SBP $(\mathrm{mmHg})$ & 141 & 8 & 138 & 10 & -3 & 132 & 9 & -9 & $-5 \cdot 8$ & $-10 \cdot 4,-1 \cdot 2$ & 0.016 \\
\hline Day DBP $(\mathrm{mmHg})$ & 83 & 6 & 83 & 9 & 0 & 79 & 8 & -4 & $-4 \cdot 0$ & $-7 \cdot 3,-0 \cdot 6$ & 0.021 \\
\hline Night SBP (mmHg) & 130 & 9 & 125 & 12 & -5 & 123 & 11 & -7 & $-2 \cdot 1$ & $-8 \cdot 2,3 \cdot 9$ & 0.473 \\
\hline Night DBP $(\mathrm{mmHg})$ & 74 & 8 & 71 & 11 & -3 & 70 & 11 & -4 & -1.9 & $-5 \cdot 6,1 \cdot 7$ & 0.284 \\
\hline
\end{tabular}

$\mathrm{PL}$, placebo; $\triangle \mathrm{PL}$, change in ABPM following PL compared with baseline; $\mathrm{NO}_{3}^{-}$, nitrate-rich beetroot juice; $\triangle \mathrm{NO}_{3}^{-}$, change in $\mathrm{ABPM}$ following $\mathrm{NO}_{3}^{-}$compared with baseline; $\mathrm{SBP}$, systolic blood pressure; DBP, diastolic blood pressure; ABPM, ambulatory blood pressure monitor.

* $P$ values derived from mixed model analysis as described.

values for 24-h, day and night SBP and DBP decreased after $\mathrm{NO}_{3}{ }^{-}$(Table 4). There was no observed treatment effect regarding either SBP or DBP (24 h, day or night).

\section{Discussion}

Daily dietary nitrate for $7 \mathrm{~d}$ was well tolerated and led to increased NO metabolites and reduced 24-h and day BP. Our trial extends the growing literature regarding the hypotensive effect of dietary nitrate as we recruited highly selected individuals with uncontrolled HTN but already established on anti-hypertensive medication. Further, we controlled for factors influencing NO, including diet, alcohol, smoking, exercise and medication.

We observed significant increases in plasma nitrite, which were greater here (126 to $732 \mu \mathrm{m}$ ) than in our pilot study (100 to $175 \mu \mathrm{M})^{(23)}$. This can be explained by the timing of phlebotomy. Here, non-fasting blood samples were taken 2-3 h after subjects consumed juice, coinciding with peak NO metabolite bioavailability $^{(14,23,27)}$.

We observed significant decreases in $24-\mathrm{h}(-8 /-4 \mathrm{mmHg})$ and day BP $(-9 /-4 \mathrm{mmHg})$ profiles but no significant effect at night. Considering that all subjects consumed juice $2-3 \mathrm{~h}$ before their morning clinic visit and the peak biochemical and physiological response to exogenous nitrate is reported at $2-3 h^{(14,23,27)}$, the lack of effect at night is not surprising.

It is noteworthy that $\mathrm{BP}$ values decreased after PL, as well as after $\mathrm{NO}_{3}^{-}$. It is possible that other bioactive components may affect BP. For example, antioxidants, flavonoids, anthyocianates, polyphenols and betaine may up-regulate nitric oxide synthase expression, decrease oxidative stress and increase NO metabolite bioavailability ${ }^{(32)}$. These components and nitrate may have individual and synergistic additive effects, even at low doses ${ }^{(32)}$. Interestingly and importantly, if BP values had not decreased after PL, the statistical significance of the anti-hypertensive effect of $\mathrm{NO}_{3}^{-}$would have been even greater.

Despite the growing interest in dietary nitrate, there remains a lack of data regarding hypertensives. An acute unblinded, uncontrolled pilot study demonstrated that a single dose of dietary nitrate $(3.5 \mathrm{mmol})$ could increase plasma nitrite by $150 \%$ and decrease $24-\mathrm{h} \mathrm{BP}(-11.2 /-9.6 \mathrm{mmHg} ; P<0.001)^{(22)}$. In a subsequent unblinded and uncontrolled, pilot study we demonstrated that 14-d dietary nitrate increased serum NO metabolites in controlled and uncontrolled hypertensives 
but selectively lowered BP and arterial stiffness in uncontrolled hypertensives only ${ }^{(23)}$. However, two recent, well-conducted trials provided conflicting evidence. A double-blind, randomised, controlled trial of drug-treated ( $n$ 34) and drug-naïve ( $n$ 34) hypertensives demonstrated that $28 \mathrm{~d}$ of $6.45 \mathrm{mmol}$ dietary nitrate significantly reduced clinic BP, home $\mathrm{BP}$ and 24-h $\mathrm{ABPM}^{(24)}$. A subsequent randomised, PL-controlled, double-blind cross-over trial assessed twenty-seven individuals with treated HTN after $7 \mathrm{~d}$ of highnitrate beetroot juice $(6.45 \mathrm{mmol})$ and $7 \mathrm{~d}$ of nitrate-depleted beetroot juice $(0.5 \mathrm{mmol})$. Despite significant increases in nitrate/nitrite, there was no difference in home $\mathrm{BP}$ or 24-h $\mathrm{ABPM}^{(33)}$.

It is noteworthy that we used double the dose of nitrate in our trial compared with these trials $(12.9 v .6 .45 \mathrm{mmol})^{(24,33)}$. We selected this dose as the nitrate content is attainable with a diet rich in vegetables ${ }^{(25)}$. For example, the Dietary Approaches to Stop Hypertension (DASH), traditional Japanese, Mediterranean and vegetarian diets are all high in nitrate (approximately $10-20 \mathrm{mmol})^{(26,34,35)}$. Further, the nitrate content of these diets has been suggested to mediate the major cardioprotective effects $^{(26,34,35)}$. National dietary data surveys show average daily nitrate intakes in the USA and Europe to be $0.5-3.0 \mathrm{mmol} / \mathrm{d}^{(36,37)}$, reflecting a processed diet in low in vegetables.

The inconsistencies may be due to differing dosing regimens, intervention periods and patient demographics. The authors suggest that use of anti-hypertensives may diminish the effect of exogenous nitrate. However, half of the subjects in the Kapil et al. trial ${ }^{(23)}$ were on anti-hypertensives as were our subjects here and in our pilot study ${ }^{(2)}$. A plausible explanation, which the authors mention ${ }^{(24)}$, is that the baseline BP was quite well controlled and therefore an additional decrease is unlikely. Indeed, we observed a similar effect in our pilot study where values in controlled hypertensives did not decrease ${ }^{(22)}$. According to a recent review, dietary nitrate appears to be most hypotensive in those with higher baseline $\mathrm{BP}^{(38)}$. We speculate that this may be owing to cross-talk between endothelial NO synthase and the nitrate-nitrite-NO pathways, whereby beneficial effects of nitrate are likely to be more pronounced when NO synthase is compromised (e.g. HTN). In addition, it has been demonstrated that the abundance and activity of a nitrite reductase enzyme is higher in those with higher $\mathrm{BP}^{(22)}$. Other factors likely to influence the effect of dietary nitrate include habitual dietary intake, baseline NO bioavailability, as well as response to exogenous nitrate. Response to exogenous nitrate is complex and determined by oral microbiota, gastric $\mathrm{pH}$ and $\mathrm{O}_{2}$ tension among others ${ }^{(39)}$.

\section{Trial strengths}

This was a double-blind, randomised, PL-controlled cross-over trial. The use of a PL juice means that we could fully blind and randomise this trial. The use of ABPM provides a robust measure of BP. There were no dropouts and there was no change in multiple measured factors known to influence NO kinetics throughout the trial, and no participant used antibiotics or mouthwash (both known inhibitors of nitrate reduction to nitrite) during the trial. Compliance with the beetroot juice was 100\%.

\section{Trial limitations}

We included a small sample. However, considering the crossover design of our trial and the samples studied in previous nitrate studies combined with our sample size calculation, we feel that twenty well-characterised subjects can provide useful information in this context. This trial was of short duration $(7 \mathrm{~d})$, designed to assess the efficacy and tolerability of daily dietary nitrate in uncontrolled hypertensives. We did not include a washout period as the pharmacokinetics of dietary nitrate reveal that biochemical and physiological effects of nitrate ingestion are absent after approximately $24 \mathrm{~h}$. Therefore, subjects completed the first arm of the study on day 8 and commenced the second arm of the study on day 9 .

\section{Conclusion}

Our results suggest that dietary nitrate has anti-hypertensive effects among uncontrolled hypertensives in conjunction with increased NO metabolites. This effect is consistent with the majority of animal model, pre-clinical and clinical data. Future studies are required to ascertain the long-term effect of dietary nitrate on BP in humans, particularly in light of evidence that dietary nitrate appears more effective in those with higher baseline BP and/or those who are treatment naïve. This intriguing concept has potential implications for multiple vulnerable populations, for example those with resistant HTN and hypertensives who refuse/cannot tolerate medication.

\section{Acknowledgements}

We wish to acknowledge the patients who agreed to participate in this research. We also wish to acknowledge the Irish Heart Foundation who supported this work. However, the Irish Heart Foundation had no role in the design, analysis or writing of this article.

C. P. K. made substantial contributions to study conception and design, data acquisition analysis and interpretation of data and has drafted the submitted article. E. D. made substantial contributions to study conception and design and analysis/ interpretation of data. P. E. J. made substantial contributions to biochemical analysis and analysis/interpretation of data. L. C. made substantial contributions to study conception and design and analysis/interpretation of data. C. P. K., E. D., P. E. J. and L. C. have provided final approval of the version to be published. E. D., P. E. J. and L. C. have revised the submitted article critically for important intellectual content. C. P. K. and L. C. have agreed to be accountable for all aspects of the work in ensuring that questions related to the accuracy or integrity of any part of the work are appropriately investigated and resolved.

The authors declare that there are no conflicts of interest.

\section{References}

1. Cutler JA, Sorlie PD, Wolz M, et al. (2008) Trends in hypertension prevalence, awareness, treatment, and control rates in United States adults between 1988-1994 and 1999-2004. Hypertension 52, 818-827.

2. Egan BM, Zhao Y \& Axon RN (2010) US trends in prevalence, awareness, treatment, and control of hypertension, 1988-2008. JAMA 303, 2043-2050. 
3. Moncada S \& Higgs EA (2006) The discovery of nitric oxide and its role in vascular biology. Br J Pharmacol 147, S193-S201.

4. Plavnik FL, Ajzen SA, Christofalo DM, et al. (2007) Endothelial function in normotensive and high-normal hypertensive subjects. J Hum Hypertens 21, 467-472.

5. Giansante C \& Fiotti N (2006) Insights into human hypertension: the role of endothelial dysfunction. J Hum Hypertens $\mathbf{2 0}$, $725-726$.

6. Linder L, Kiowski W, Bühler FR, et al. (1990) Indirect evidence for release of endothelium-derived relaxing factor in human forearm circulation in vivo. Blunted response in essential hypertension. Circulation 81, 1762-1767.

7. Forte P, Copland M, Smith LM, et al. (1997) Basal nitric oxide synthesis in essential hypertension. Lancet 349, 837-842.

8. Kohno M, Yokokawa K, Minami M, et al. (1999) Plasma levels of nitric oxide and related vasoactive factors following longterm treatment with angiotensin-converting enzyme inhibitor in patients with essential hypertension. Metabolism $\mathbf{4 8}$, 1256-1259.

9. Ghasemi A, Zahediasl S, Syedmoradi L, et al. (2011) Association between serum nitric oxide metabolites and hypertension in a general population. Int Angiol 30, 380-387.

10. Shiekh GA, Ayub T, Khan SN, et al. (2011) Reduced nitrate level in individuals with hypertension and diabetes. J Cardiovasc Dis Res 2, 172-176.

11. Heiss C, Lauer T, Dejam A, et al. (2006) Plasma nitroso compounds are decreased in patients with endothelial dysfunction. J Am Coll Cardiol 47, 573-579.

12. Casey DP, Beck DT \& Braith RW (2007) Systemic plasma levels of nitrite/nitrate (NOx) reflect brachial flow-mediated dilation responses in young men and women. Clin Exp Pharmacol Physiol 34, 1291-1293.

13. Larsen FJ, Ekblom B, Sahlin K, et al. (2006) Effects of dietary nitrate on blood pressure in healthy volunteers. N Engl J Med 355, 2792-2793.

14. Webb AJ, Patel N, Loukogeorgakis S, et al. (2008) Acute blood pressure lowering, vasoprotective, and antiplatelet properties of dietary nitrate via bioconversion to nitrite. Hypertension $\mathbf{5 1}$, 784-790.

15. Gilchrist M, Shore AC \& Benjamin N (2011) Inorganic nitrate and nitrite and control of blood pressure. Cardiovasc Res 89, 492-498.

16. Siervo M, Lara J, Ogbonmwan I, et al. (2013) Inorganic nitrate and beetroot juice supplementation reduces blood pressure in adults: a systematic review and meta-analysis. J Nutr $\mathbf{1 4 3}$, 818-826.

17. Hobbs DA, George TW \& Lovegrove JA (2013) The effects of dietary nitrate on blood pressure and endothelial function: a review of human intervention studies. Nutr Res Rev 26, 210-222.

18. d'El-Rei J, Cunha AR, Trindade M, et al. (2016) Beneficial effects of dietary nitrate on endothelial function and blood pressure levels. Int J Hypertens, 6791519.

19. Gee LC \& Ahluwalia A (2016) Dietary nitrate lowers blood pressure: epidemiological, pre-clinical experimental and clinical trial evidence. Curr Hypertens Rep 18, 17.

20. Bahadoran Z, Mirmiran P, Ghasemi A, et al. (2016) Association between dietary intakes of nitrate and nitrite and the risk of hypertension and chronic kidney disease: Tehran Lipid and Glucose Study. Nutrients $\mathbf{8}, 12$.

21. Golzarand M, Bahadoran Z, Mirmiran P, et al. (2016) Consumption of nitrate-containing vegetables is inversely associated with hypertension in adults: a prospective investigation from the Tehran Lipid and Glucose Study. J Nephrol 29, 377-384.
22. Ghosh SM, Kapil V, Fuentes-Calvo I, et al. (2013) Enhanced vasodilator activity of nitrite in hypertension: critical role for erythrocytic xanthine oxidoreductase and translational potential. Hypertension 61, 1091-1102.

23. Kerley CP, Dolan E \& Cormican L (2017) Nitrate-rich beetroot juice selectively lowers ambulatory pressures and LDL cholesterol in uncontrolled but not controlled hypertension: a pilot study. Ir J Med Sci 186, 895-902.

24. Kapil V, Khambata RS, Robertson A, et al. (2015) Dietary nitrate provides sustained blood pressure lowering in hypertensive patients: a randomized, phase 2, double-blind, placebo-controlled study. Hypertension 65, 320-327.

25. Gilchrist M, Winyard PG, Fulford J, et al. (2014) Dietary nitrate supplementation improves reaction time in type 2 diabetes: development and application of a novel nitrate-depleted beetroot juice placebo. Nitric Oxide 40, 67-74.

26. Sobko T, Marcus C, Govoni M, et al. (2010) Dietary nitrate in Japanese traditional foods lowers diastolic blood pressure in healthy volunteers. Nitric Oxide 22, 136-140.

27. Kerley CP, Cahill K, Bolger K, et al. (2015) Dietary nitrate supplementation in COPD: an acute, double-blind, randomized, placebo-controlled, crossover trial. Nitric Oxide $\mathbf{4 4}$, 105-111.

28. Lidder S \& Webb AJ (2013) Vascular effects of dietary nitrate (as found in green leafy vegetables and beetroot) via the nitrate-nitrite-nitric oxide pathway. Br J Clin Pharmacol 75, 677-696.

29. Moshage H, Kok B, Huizenga JR, et al. (1995) Nitrite and nitrate determinations in plasma: a critical evaluation. Clin Chem 41, 892-896.

30. Kleinbongard P, Dejam A, Lauer T, et al. (2003) Plasma nitrite reflects constitutive nitric oxide synthase activity in mammals. Free Radic Biol Med 35, 790-796.

31. Maher AR, Arif S, Madhani M, et al. (2013) Impact of chronic congestive heart failure on pharmacokinetics and vasomotor effects of infused nitrite. Br J Pharmacol 169, 659-670.

32. Rodriguez-Mateos $\mathrm{A}$, Hezel $\mathrm{M}$, Aydin $\mathrm{H}$, et al. (2015) Interactions between cocoa flavanols and inorganic nitrate: additive effects on endothelial function at achievable dietary amounts. Free Radic Biol Med 80, 121-128.

33. Bondonno CP, Liu AH, Croft KD, et al. (2015) Absence of an effect of high nitrate intake from beetroot juice on blood pressure in treated hypertensive individuals: a randomized controlled trial. Am J Clin Nutr 102, 368-375.

34. Nadtochiy SM \& Redman EK (2011) Mediterranean diet and cardioprotection: the role of nitrite, polyunsaturated fatty acids, and polyphenols. Nutrition 27, 733-744.

35. Lin PH, Allen JD, Li YJ, et al. (2012) Blood pressure-lowering mechanisms of the DASH dietary pattern. J Nutr Metab 2012, 472396.

36. Mensinga TT, Speijers GJ \& Meulenbelt J (2003) Health implications of exposure to environmental nitrogenous compounds. Toxicol Rev 22, 41-51.

37. Gangolli SD, van den Brandt PA, Feron VJ, et al. (1994) Nitrate, nitrite and $\mathrm{N}$-nitroso compounds. Eur J Pharmacol 292, 1-38.

38. Lara J, Ashor AW, Oggioni C, et al. (2016) Effects of inorganic nitrate and beetroot supplementation on endothelial function: a systematic review and meta-analysis. Eur J Nutr 55, 451-459.

39. Kerley CP (2017) Dietary nitrate as modulator of physical performance and cardiovascular health. Curr Opin Clin Nutr Metab Care 20, 440-446. 